\title{
1 A bibliometric analysis of Soil remediation Based on Massive research literature data During
}

2 1988-2018

3 


\section{Abstract}

Soil is an important part of the ecosystem with significant roles that help human population sustain.

Research on prevention and remediation of soil pollution has been carried out when 1985. This study

analyzed the 1988-2018 soil remediation dataset in the Web of Science database by bibliometric

remediation in the world. To further identify the major soil contamination topics, we employed social network analysis. The results indicate that the field of soil remediation has entered a stage of rapid progress. The United States has a strong overall strength with the largest number of published articles and larger impact. China ranks second. We identified Journal of hazardous materials as the most influential journal and Chinese academy of sciences as the most influential institution. Academic cooperation showed an increasing trend at the author, institutional, and national levels with an average level of cooperation of $3.57,1.66$, and 1.16 , respectively. However, the growth rate of cooperation at the national level is relatively low. In addition, the frequency and co-word analyses of keywords revealed the important research topics. "heavy metals", "PAH", "bioremediation","Phytoremediation" and "Electrokinetic remediation" were identified as the hot topics. The findings of this study will help researchers understand the status of soil remediation as well as provide guidance for future research. 


\section{Introduction}

Soil is an important dependence of human survival. contaminated soil which polluted by heavy metals, agricultural inputs and solid waste, deteriorates the environment and restricts human development[1-3]. Soil contamination and remediation are global problems that have attracted the attention of governments and researchers[4]. In order to protect soil and prevent further deterioration, various studies have been conducted on remediation of contaminated soil. Many soil remediation technologies have been developed during the past few decades on different aspects such as chemistry, biology, agroecology, and electrodynamics[5,6]. During this period, new research ideas, methods, and means were introduced, and the remediation technology system was improved. At the same time, the intersection of discipline such as soil, engineering, chemistry and new materials promoted the rapid progress in soil remediation research[7]. However, the future of soil remediation technologies is uncertain and the need for multidisciplinary research is high. To gain research progress in soil remediation, we should focus on the key processes in soil remediation and break through the bottlenecks. We should explore new remediation technologies and perform a quantitative analysis of the relevant information in the field.

Bibliometrics can explores structures, characteristics, and laws of science and technology [8]. We used bibliometric method to analyze current research and the development trends in the field of soil remediation including total number of articles, countries' performances, productive journals, performances of authors and institutios, citation, and extent of academic collaboration. This work will fill the gap in the field of soil remediation. Using frequency analysis and co-occurrence analysis of high-frequency keywords will help other researchers grasp the essence of advanced topics in this 
field. Based on the analysis, potential limitations and directions were derived to provide guidance to plan and implement future research.

\section{Materials and methods}

\section{Data source}

Data used in this study were taken from the Web of Science (WOS) core collection including Science Citation Index Expanded, Social Sciences Citation Index, Conference Proceedings Citation Index-Science, Conference Proceedings Citation Index-Social Science \& Humanities, and Emerging Sources Citation Index. We searched the title, abstract, and keywords of 13891 published articles using 1988-2018 as the time phase, "soil remediation" as the keyword, and "subject" as the field.

The search date is January 18, 2019. The WOS derived document records included titles, authors, abstracts, and keywords. These indicators were analyzed using BibExcel, Ucinet and VOSviewer.

A general statistical analysis was performed on national distribution, journals, topics, authors, institutions, and citations. In addition, impact factor, academic cooperation, and national comprehensive strength were used to reflect the current academic impact of a country and of an author. Research and development in the field of soil remediation was analyzed, which will help researchers and policy makers attain an overall understanding of the subject.

\section{Impact factor}


As the most commonly used assessment tool in bibliometrics, impact factor helps assess the merit of journals, authors, institutions, and countries [9].We collected the impact factors from the ISI Journal Citation Reports to evaluate the quality of the journals.

\section{Academic cooperation}

Cooperation in scientific research is improving at all levels and in all areas, and this is a common indicator to measure closeness of collaboration in scientific research [10]. The indicators at all levels (author, institution, and nation) were used to calculate the degree of academic cooperation in the field of soil remediation. Equations used for calculation are as follows:

(2) Institutional cooperation:

$$
C_{A}=\frac{\sum_{i=1}^{N} \alpha_{i}}{N}
$$

(3) National cooperation:

$$
C_{C}=\frac{\sum_{\mathrm{i}=1}^{N} \gamma_{i}}{N}
$$

Where, $G_{A}, G_{I}$, and $G_{C}$ represent the degree of cooperation by author, institution, and country, respectively; $\alpha_{\mathrm{i}}, \beta_{\mathrm{i}}$, and $\gamma_{\mathrm{i}}$ represent the number of authors, institutions, and countries contributing to each paper, respectively; $\mathrm{N}$ represents the total number of articles in the field.

\section{Academic scale}


Academic influence and academic competitiveness reflect a country's comprehensive research strength. Four indicators were selected to assess national comprehensive research strength: (1) total number of articles (2) total citations (3) number of authors, and (4) number of research institutions. By calculating the standard scores of these four indicators, the combined score of each country was obtained, and the formulae used for calculation are as follows:

(4) Standard score:

$$
T_{i j}=\frac{x_{i j}-\overline{x_{i j}}}{\sqrt{\frac{\sum_{i}\left(x_{i j}-\overline{x_{j}}\right)^{2}}{M}}}+1
$$

$$
\text { (5) Comprehensive score: } T_{\mathrm{i}}=\sum_{j} T_{i j}
$$

Where, $T_{i j}$ represents the standard score of indicator $j$ in country $i$; $x_{i j}$ represents the original score of indicator $\mathrm{j}$ in country $\mathrm{i} ; \overline{\mathrm{x}}_{\mathrm{ij}}$ represents its average score; $T_{\mathrm{i}}$ represents the sum of the standard scores in country $\mathrm{i}$; and $\mathrm{M}$ represents the number of countries.

\section{Results}

\section{Contribution of country}

The number of articles in a specific area is an important indicator to assess development trend. Analysis revealed that a total of 13,891 journal articles were retrieved from 148 countries and regions including England, Scotland, Wales, and Northern Ireland; China included only mainland China, and Hong Kong, Macao, and Taiwan were analyzed as separate regions. Different colors represent the number of articles in different geographical regions(Fig 1), the darker the color, the 


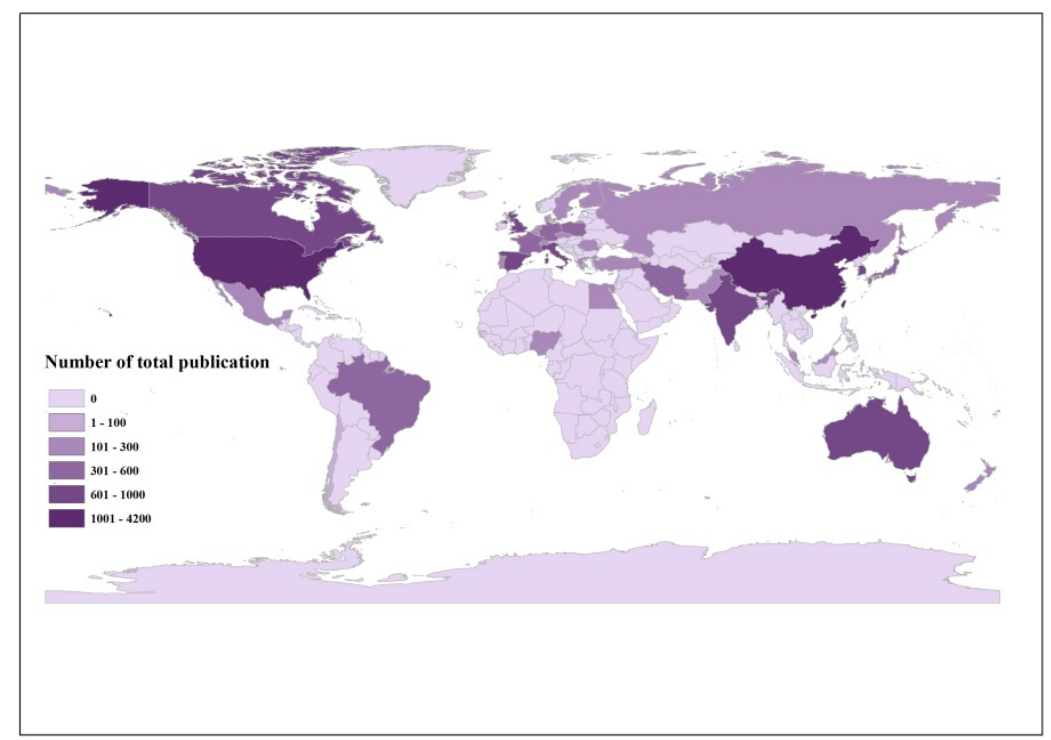

114 Figure 1 World map showing the distribution of research articles

115 The number of articles in the soil remediation field has grown rapidly over time (Fig 2 ), and the

116 growth happened in three phases. Only a few developed countries such as the United States and

117 Canada published few articles in the early beginning phase (1988 to 1998). In order to improve the

118 quality of cultivated soil, healthy human living environment, many countries began to pay attention

119 and study soil issues in the stable development phase (1998 to 2008). China's soil remediation 


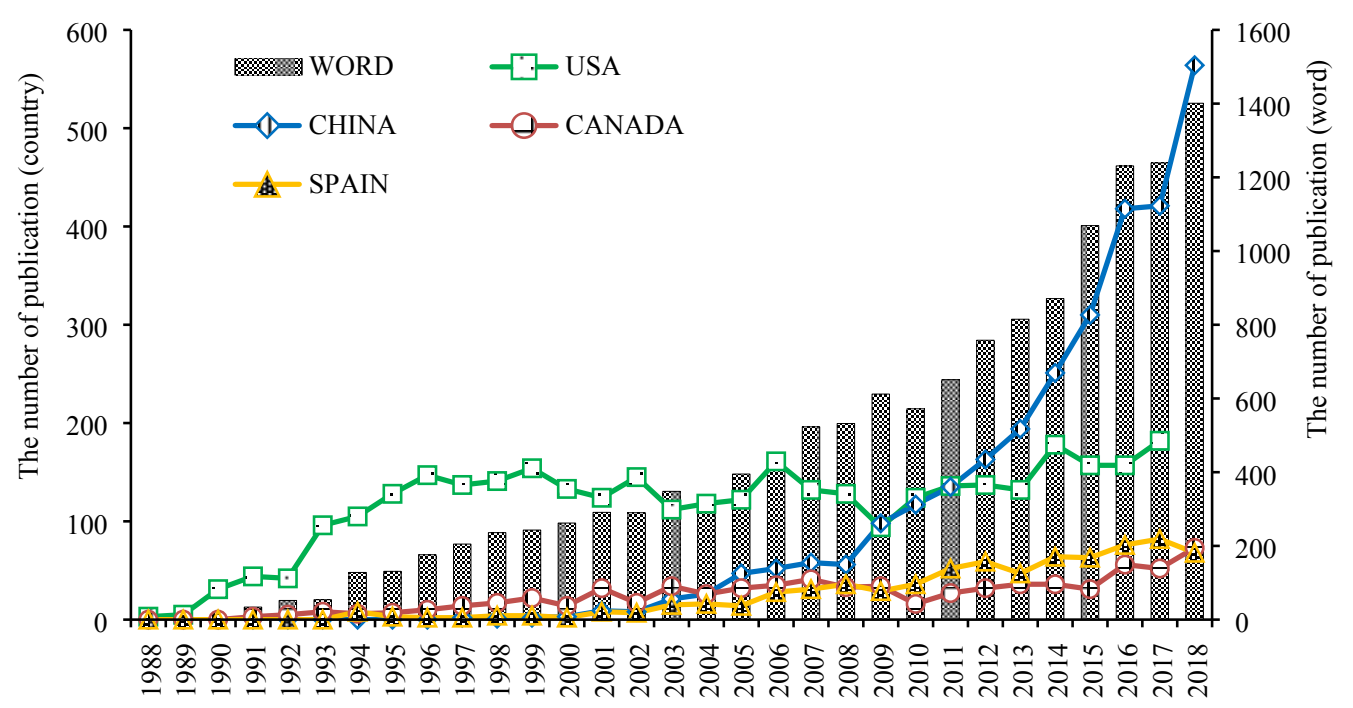

Figure 2 Distribution of major publishing countries

\section{Productive institutions}

6637 institutions contributed to the soil remediation field. Among developing countries, four institutions among the 10 most published research institutions were in China (Table 1), the Chinese

Academy of Sciences and the University of Chinese Academy of Sciences ranked first and third.

Other research institutions were from developed countries, four from the United States and two from

France. The Chinese Academy of Sciences contributed 706 articles $(56.54 \%$ of the total number of

Chinese articles). This indicates that Chinese Academy of Sciences is in a leading position in the

field of soil remediation.

Table 1 Productive institutions during 1988-2018.

\begin{tabular}{ccccc}
\hline RANK & Institution & Country & TP & TPRW $(\%)$ \\
\hline 1 & Chinese Academy of Sciences & China & 706 & 5.1 \\
2 & United states department of energy doe & USA & 369 & 2.7 \\
3 & University of chinese academy of sciences & China & 234 & 1.7 \\
4 & Centre national de la recherche scientifique & France & 230 & 1.7 \\
5 & Consejo Superior de Investigaciones Cientificas & France & 227 & 1.6 \\
6 & university of california system & USA & 206 & 1.5 \\
7 & Institute of soil science & China & 204 & 1.5
\end{tabular}


Table 2 Productive authors during 1988-2018.

\begin{tabular}{cccccc}
\hline Rank & Authors & Country & TP & TC & CPP \\
\hline 1 & Ottosen LM & Denmark & 82 & 1574 & 19.2 \\
2 & Beak K & Korea & 70 & 1091 & 15.59 \\
3 & Reedy KR & USA & 70 & 2347 & 33.53 \\
4 & Naidu R & Australia & 66 & 1032 & 15.64 \\
5 & Canizares P & Spain & 59 & 766 & 13.15 \\
6 & Rodrigo MA & Spain & 59 & 736 & 12.47 \\
7 & Tsang DCW & Hong Kong & 57 & 981 & 11.21 \\
8 & Luo YM & China & 56 & 1173 & 20.95 \\
9 & Lestan D & Slovenia & 52 & 1485 & 28.56 \\
10 & OK YS & Korea & 52 & 1732 & 33.31 \\
\hline
\end{tabular}

Note: TP is the number of total articles; TC is the number of total citations; CPP is citations per publication. The most productive author was Ottosen LM (Denmark) has contributed to 82 articles. He mainly studied the use of electrodialysis technology and the use of electricity to deal with copper, lead, zinc,

Note: TP is the number of total articles; TPRW(\%) is the ratio of the number of journal's publications in which institution to the total number of articles.

\section{Productive authors}

32534 authors contributed to the soil remediation field. The authors with the most recent articles were from Denmark, and the productive authors were from other developed countries such as South Korea, United States, Australia, and Spain among the top 10 authors in the field of soil remediation(Table 2).

\begin{tabular}{ccc} 
China & 179 & 1.3 \\
USA & 177 & 1.3 \\
USA & 175 & 1.3 \\
\hline
\end{tabular}


147

Table 3 Top fifteen productive journals during 1998-2018.

\begin{tabular}{cccccc}
\hline Rank & Journal & TP & TPR $(\%)$ & IF & TC \\
\hline 1 & Journal of hazardous materials & 822 & 5.92 & 6.434 & 24491 \\
2 & Chemosphere & 758 & 5.46 & 4.427 & 21607 \\
3 & Environmental science and pollution research & 529 & 3.81 & 2.8 & 3985 \\
4 & Environmental science technology & 482 & 3.47 & 6.653 & 27199 \\
5 & Science of the total environment & 400 & 2.88 & 4.61 & 9032 \\
6 & Water air and soil pollution & 369 & 2.66 & 1.769 & 5574 \\
7 & Environmental pollution & 303 & 2.18 & 4.358 & 12079 \\
8 & International journal of phytoremediation & 239 & 1.70 & 4.005 & 3371 \\
9 & Journal of environmental management & 223 & 1.61 & 1.886 & 2592 \\
10 & Journal of contaminant hydrology & 206 & 1.48 & 2.405 & 7230 \\
\hline
\end{tabular}
articles. He analyzed the effect of electrolyte regulation of acidic and alkaline solutions on electroremediation of contaminated soil [14].

\section{Journals performance}

1423 academic journals retrieved in the soil remediation field. These articles related to environmental science, soil contamination and botany. Journal of hazardous materials had 822 articles (5.9\%)was the most published journal (Table 3). Chemosphere had 758 articles (5.5\%) was the second most published journal. Environmental science and technology ranked fourth among all publications in all journals, however it has the largest impact factor (6.653) and had the most citations (27199). 
relatively low growth rates.

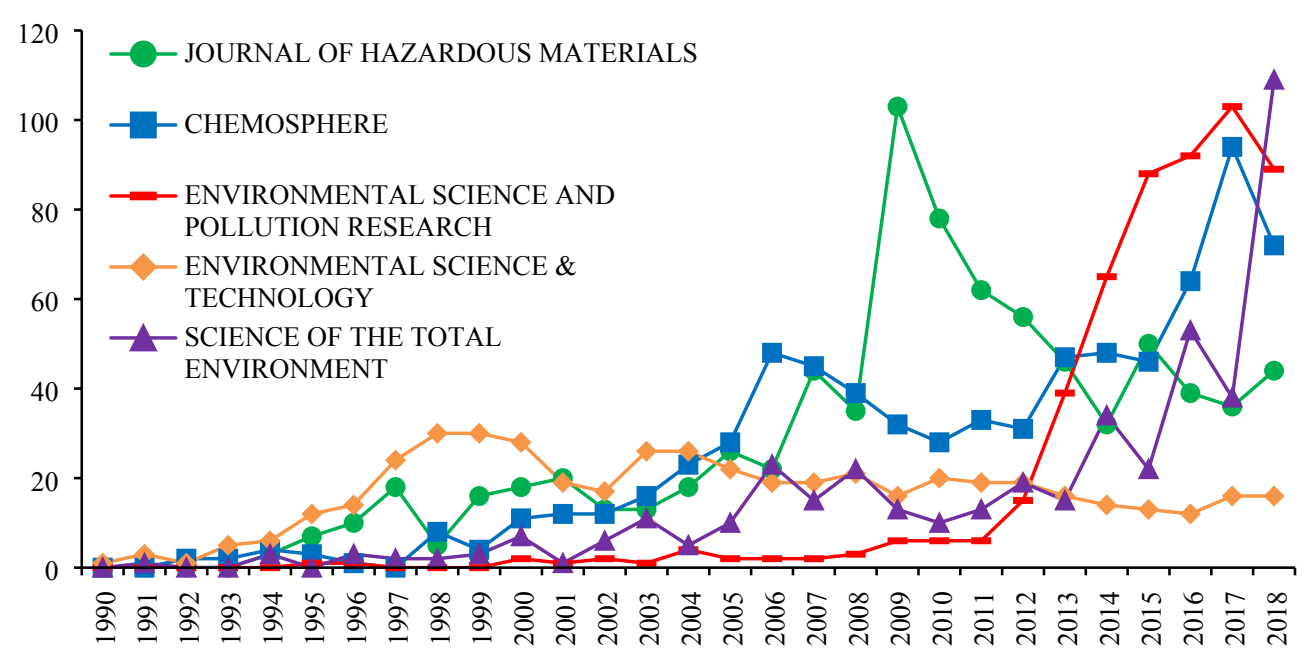

Figure 3 Trend of top five journals

\section{Subjects performance}

Lists Environmental sciences ecology was the most popular subject with 8550 articles $(61.5 \%)$ followed by Engineering and Water resources (29.1\% and 11.6\%) among the top 10 subjects closely related to the field of soil remediation(Table 4). Articles in this field focused on natural science subjects especially environmental science, ecology, geology, and meteorology and few social science subjects such as business and economics. Some domain-specified subjects including 
Table 4 Distribution of subjects during 1988-2018.

\begin{tabular}{cccc}
\hline Rank & Subject & TP & TPR(\%) \\
\hline 1 & Environmental sciences ecology & 8550 & $61.5 \%$ \\
2 & Engineering & 1043 & $29.1 \%$ \\
3 & Water resources & 1612 & $11.6 \%$ \\
4 & Agriculture & 1348 & $9.7 \%$ \\
5 & Chemistry & 1176 & $8.4 \%$ \\
6 & Geology & 863 & $6.2 \%$ \\
7 & Biotechnology applied microbiology & 781 & $5.6 \%$ \\
8 & Meteorology atmospheric sciences & 434 & $3.1 \%$ \\
9 & Science technology other topics & 433 & $3.1 \%$ \\
10 & Toxicology & 404 & $2.9 \%$ \\
\hline
\end{tabular}

Note: TP is the number of total articles; TPR(\%) is the ratio of the number of journal's publications to the total number of articles. cooperation was Significant (3.57). Growth in national cooperation was slow due to the soil

chemistry, agriculture, plants, and toxicology also published numerous articles because of their sensitivity to soil remediation.

\section{Academic collaboration}

The degree of academic cooperation reflects the degree of academic research in scientific research in this field. The degree of cooperation between authors, institutions, and countries was calculated using formulae (1), (2), and (3). Authors, institutions, and countries had cooperation levels of 3.57, 1.66, and 1.16, respectively, which indicate that 3.57 authors, 1.66 institutions, and 1.16 countries contributed to each article (Fig 4).The level of cooperation constantly improved, and the authors' contamination problems are more concentrated in individual countries. 


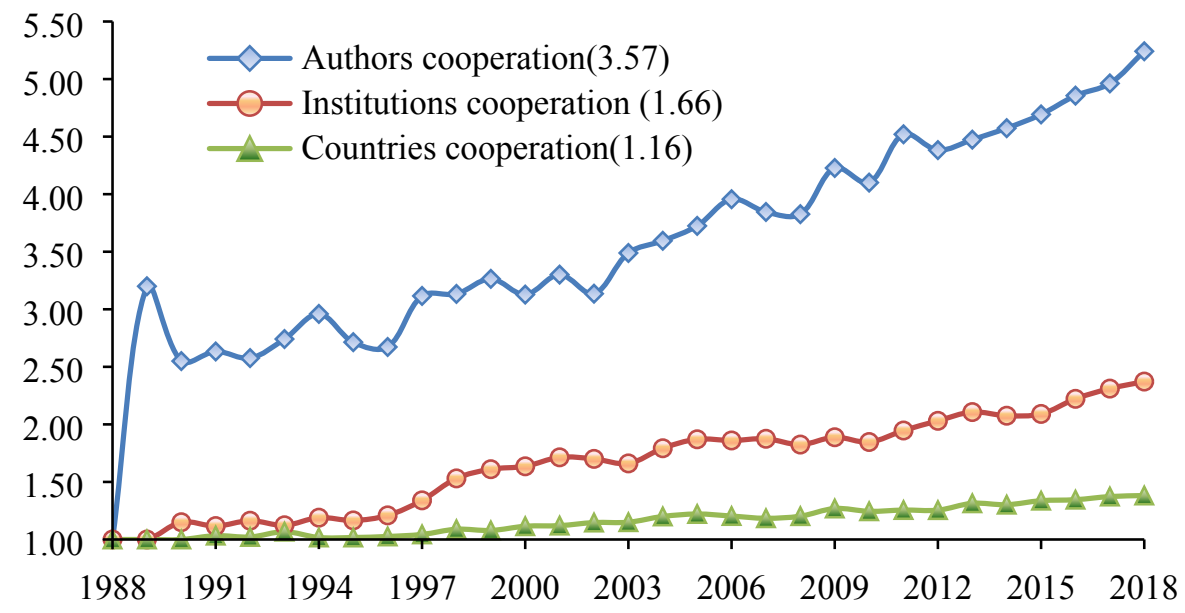

\section{Keyword clustering and frequency analysis}

$\mathrm{m}_{\max }=4372$. In this study, $\mathrm{n}=50$ implies that the keywords which are cited more than 50 times sre the

labeled the number of occurrence for each keyword (Table 5).

Table 5 Frequency of keywords in soil remediation during 1988-2018.

\begin{tabular}{|c|c|c|}
\hline Category & Representative keywords & frequency \\
\hline & Heavy metals(816),Cadmium(300),Heavy metal(273),Arsenic(270),Lead(261), & \multirow{4}{*}{3022} \\
\hline Inorganic & Metals(141),Chromium(133),Copper(129),Zinc(104),Toxicity(96),mercury(92), & \\
\hline \multirow[t]{2}{*}{ pollution } & Salinity(76),Persulfate(57),Phytotoxicity(57),Nickel(55),Uranium(55), & \\
\hline & Hexavalent chromium(54),Acid mine drainage(53) & \\
\hline Bioremediation & Phytoremediation(719), Bioremediation(633),Biodegradation(347),Biochar(262), & \\
\hline remediation & Bioavailability(223),Bioaugmentation(115),biosurfactant(106),Bacteria(62), & 2585 \\
\hline technology & Microbial community(59),Bioaccumulation(59) & \\
\hline
\end{tabular}


Heavy metals entered the soil with the rapid development of the global economy. Anthropogenic activities such as mining, industrial production, agriculture, and transportation are the major sources of heavy metals in soil. They cannot be completely removed from the soil by degradation and has caused soil contamination problems in many countries [15]. So "heavy metal" was a prominent keyword in soil contamination. Cadmium, arsenic, lead, chromium, and zinc have been the focus of remediation research followed by toxicity and salinization [16].

\section{Bioremediation remediation technology}

211 Bioremediation uses plants, animals, and microorganisms in the soil to absorb, degrade, and

212 transform the soil Contaminants. "Phytoremediation" and "bioremediation" have been the focus of

213 scholars after 2010 [17]. Bioremediation degrades Contaminants in situ at a low cost of remediation

214 and with no secondary pollution. Due to the limitations of single remediation techniques, joint

215 remediation techniques such as co-bioremediation remediation, physical-biological remediation, and

216 chemical-biological remediation have been considered by some scholars.

\section{Physical remediation technology}


218 In situ soil washing, adsorption, immobilization, and other electric methods are the most studied

219 physical methods [18]. Soil washing remediation mainly improves extraction efficiency by finding

220 new eluents. Electrokinetic remediation was the most concerned chemical remediation technologys.

221 In addition to new electrode technology which was represented by electrolyte optimization and

222 approaching anode, Combined technology was represented by electric-permeable wall began to

223 appeared and developed rapidly.

\section{Organic pollution}

Currently, more attention is paid polycyclic aromatic hydrocarbons, tocrude oils and petroleum

hydrocarbons in organic pollution [19]. Pollution form Atrazine, chlorpyrifos and

USA. With the increasing consumption of US military explosives, greatly studied researched on the petroleum, crude oil, and Petroleum hydrocarbons.

\section{Chemical remediation technology}

232 The main research in the field of chemical remediation technology was based on the chemical

233 properties of pollutants or contaminated media. This method changed the chemical properties by the application of various chemical reagents, and separates the pollutants. Surfactants solubilize and

235 elute soil contaminants, and EDTA complexes with the salts of heavy metals and increase the 


\section{Co-occurrence and network analysis of keywords}

240 Co-occurrence analysis of high frequency keywords was performed using VOSviewer. The common

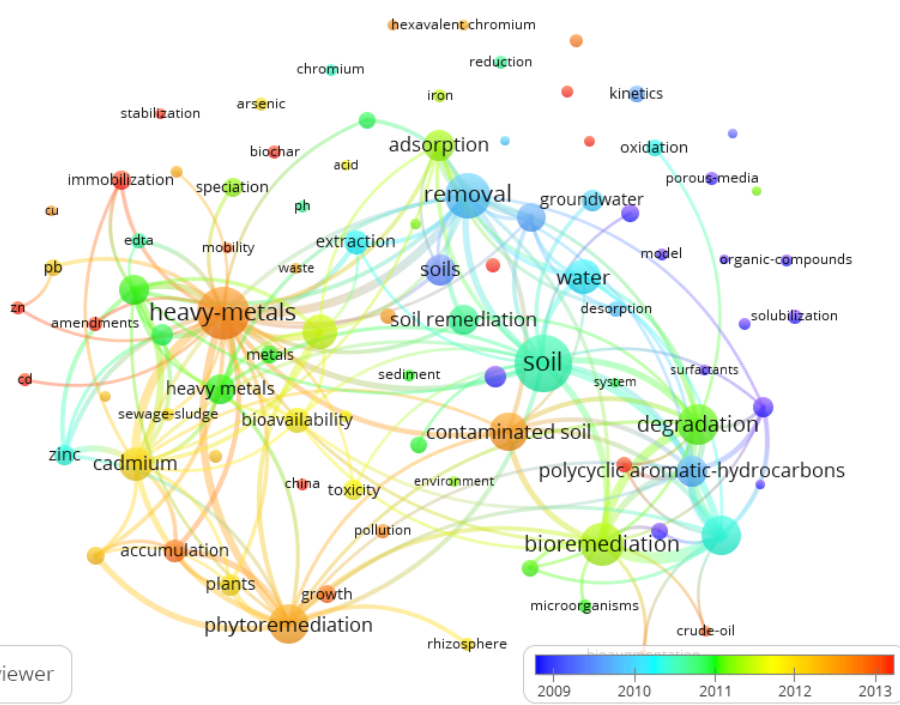

Figure 5 Co-occurrence map of keywords in the field of soil remediation

Each keyword is represented by a circle in the visualization result of keyword average time

distribution (Fig 5). The diameter of the circle and the size of the label indicate the appearance of

keywords. The bigger the circle, the more the number of occurrences of the keyword [20].The together. connection and reflects its central position in research. Large-scale keywords such as 
network. Among all these keywords, the number of connections between "heavy metals", "cadmium", and "removal" was the most. This indicates their relevance and these three keywords or two of them usually appear together in the same research and most scholars focused on these issues. Another keyword group including "phytoremediation", "bioremediation", and "contaminated soil" also showed strong correlation, which indicates their relevance in soil remediation research.

Change in color indicates the trend in hot topics in this field. Blue represents the keywords that were released before 2009, such as "removal", "grandwater", "polycyclic aromatic-hydrocarbons" and "phenanthrene". These words focused on PAH pollution and the migration mechanism of contaminants in soil. Green represents the keywords around 2011. Increase in soil contamination threatens the living environment and food security. Therefore, scholars have been paying more attention to soil contamination and remediation. The research techniques used were mainly bioremediation technologies including phytoremediation. As an important source of soil contamination, heavy metals continue to receive widespread attention. Studies have focused on "biochar", "China", "sewage", and other specific topics and regions since 2013, rather than abstract and macro themes. These trends indicate that major research in the field of soil remediation is shifting from a contamination mechanism to technology application.

\section{Conclusions}

Based on the WOS core database, the overall research development in the field of soil remediation from 1988 to 2018 was analyzed using bibliometric methods. 
articles indicates that soil remediation is receiving increasing attention. At the national level, the United States had high overall strength with the largest number of articles and greater academic influence. As a representative of developing countries, China's institutions and authors performed well by contributing more number of articles. The top five most published journals contributed $21.5 \%$ of all articles in the field in which Journal of hazardous materials was the most published journal. In addition, soil remediation included multidisciplinary fields, and environmental science ecology, engineering, and water resources were the top three subjects that published the most articles. Ottosen LM (Denmark), Reddy KR (the United States) and Baek K (Korea) were the authors with the more number published articles in this field. Academic cooperation showed an increasing trend at the author, institutional, and national levels with an average level of cooperation of 3.57, 1.66, and 1.16, respectively.

Cluster analysis and frequency analysis of the keywords indicate that the hot topics in this field were heavy metals, phytoremediation, bioremediation, electrodynamics, cadmium, leaching, solidification, and polycyclic aromatic hydrocarbons. According to the co-word analysis, "heavy metals" keyword had the maximum connection among all keywords and often appeared simultaneously with other keywords reflecting heavy metals as the core issue in the field. Trends in the hot topics in this field were discussed through the analysis of the keywords in published works. We found that research focus is shifting from the mechanism of pollutant transport in contaminated soils to the application of comprehensive repair technologies such as bioremediation technology and electric remediation. Meanwhile, research focused on specific micro-level issues and quantitative analysis in areas and regions. This study will help researchers understand the development trends in soil remediation research and provide guidance for future research. 


\section{Acknowledgement}

This work was Supported by the Scientific Research Item of Shaanxi Provincial Land Engineering

\section{Reference}

1. Chen, H., Teng, Y., Lu, S., Wang, Y., Wang, J. (2015). Contamination features and health risk of soil heavy metals in China. Science of the Total Environment, 512-513,143-153.

2. Ni, Z., Wang, S. (2015). Economic development influences on sediment-bound nitrogen and phosphorus accumulation of lakes in China. Environmental Science and Pollution Research, 22,

3. Khatri, N., Tyagi, S. (2015). Influences of natural and anthropogenic factors on surface and groundwater quality in rural and urban areas. Frontiers in Life Science, 8, 23-39. sediments by the combined application of a biodegradable non-ionic surfactant and complexing 
5. Guarino, C., Sciarrillo, R. (2017). Effectiveness of in situ application of an Integrated multi-contaminated soils. Ecological Engineering, 99, 70-82.

6. Ait Ahmed, O., Derriche, Z., Kameche, M., Bahmani, A., Souli, H., Dubujet, P., Fleureau, J.M. (2015). Electro-Remediation of Lead Contaminated Kaolinite: An Electro-Kinetic Treatment. Chemical Engineering and Processing: Process Intensification, S0255270115301537.

7. Mao, G., Shi, T., Zhang, S., Crittenden, J., Guo, S., Du, H. (2018). Bibliometric analysis of insights into soil remediation. Journal of Soils and Sediments, 18, 2520-2534.

8. Garousi, V., Mantyla, M. V. (2016). Citations, research topics and active countries in software engineering: A bibliometrics study. Computer Science Review, 19, 56-77.

9. Paulus, F. M., Rademacher, L., Schäfer, T., Müller-Pinzler, L., Krach, S. (2015). Journal Impact

10. Wei, Y. M., Yuan, X. C., Wu, G., Yang, L. X. (2014) Climate Change Risk Assessment:A bibliometric Analysis Based on Web of Science. Bulletin of National Natural Science

11. Jakobsen, M. R., Fritt-Rasmussen, J., Nielsen, S., Ottosen, L. M. (2004). Electrodialytic removal of cadmium from wastewater sludge. Journal of Hazardous Materials, 106, 127-132.

12. Jensen, P. E., Ottosen, L. M., Pedersen, A. J., Speciation Of Pb In Industrially Polluted Soils. 
13. Reddy, K. R., Parupudi, U. S., (1997). Devulapalli S N , et al. Effects of soil composition on the removal of chromium by electrokinetics. Journal of Hazardous Materials, 55, 135-158.

14. Baek, K., Kim, D. H., Park, S. W., Ryu, B. G., Bajargal, T., Yang, J. (2009). Electrolyte conditioning-enhanced electrokinetic remediation of arsenic-contaminated mine tailing. Journal of Hazardous Materials, 161, 457-462.

15. Chen, M., Xu, P., Zeng, G., Yang, C., Huang, D., Zhang, J. (2015). Bioremediation of soils contaminated with polycyclic aromatic hydrocarbons, petroleum, pesticides, chlorophenols and heavy metals by composting: Applications, microbes and future research needs. Biotechnology Advances, 33, 745-755.

16. Toth, G., Hermann, T., Da Silva, M. R, Montanarella, L. (2016). Heavy metals in agricultural soils of the European Union with implications for food safety. Environment International, 88, 299-309.

17. Hussain, I.,Aleti, G., Naidu, R., Puschenreiter, M. (2018). Microbe and plant assisted-remediation of organic xenobiotics and its enhancement by genetically modified organisms and recombinant technology: A review. Science of The Total Environment, 628, 1582-1599.

18. Derakhshan, N., Z , Jung, M. C., Kim, K. H. (2017).Remediation of soils contaminated with heavy metals with an emphasis on immobilization technology. Environmental Geochemistry and Health, 40, 927-953

19. Ivshina, I., Kostina, L., Krivoruchko, A. Kuyukina, M., Peshkurc, T., Anderson, P. et al. (2016).Removal of polycyclic aromatic hydrocarbons in soil spiked with model mixtures of 

231. Journal of Hazardous Materials, S0304389416302229.

20. Wang, Z., Zhao, Y., Wang, B. (2018). A bibliometric analysis of climate change adaptation based on massive research literature data. Journal of Cleaner Production, 199, 1072-1082. 


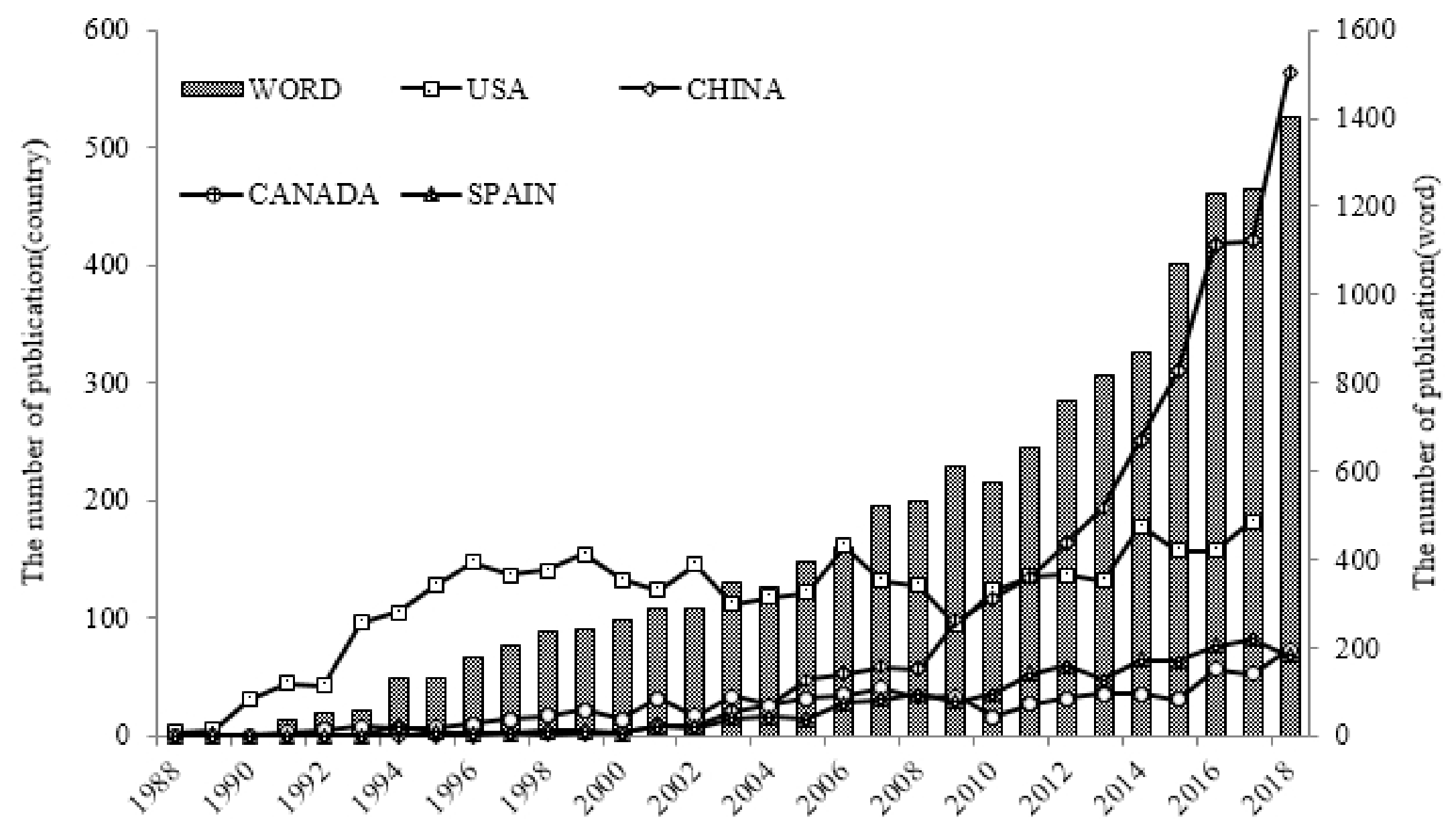

\section{Figure 2}




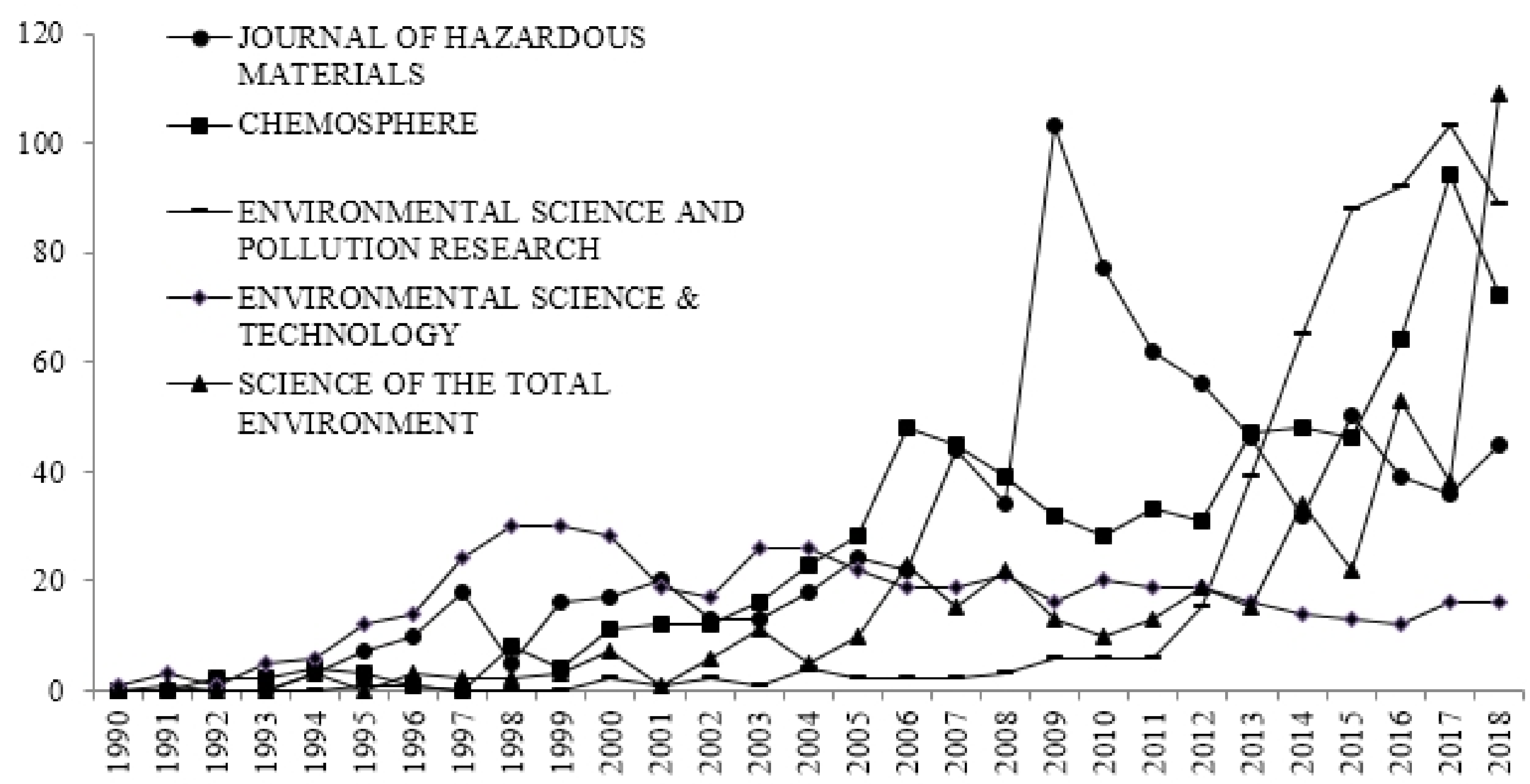

Figure 3 
chromium

stabilization

arsenic

iron

\section{biochar}

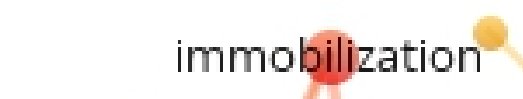

$\mathrm{Cu}$

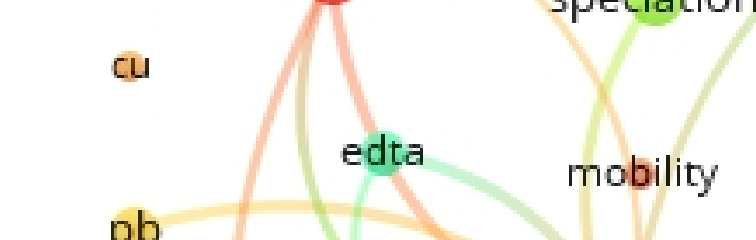
speciation mobility

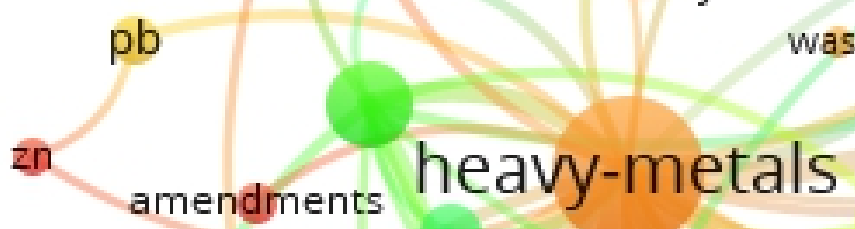
ph

\section{extraction

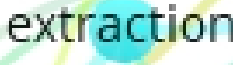
aste
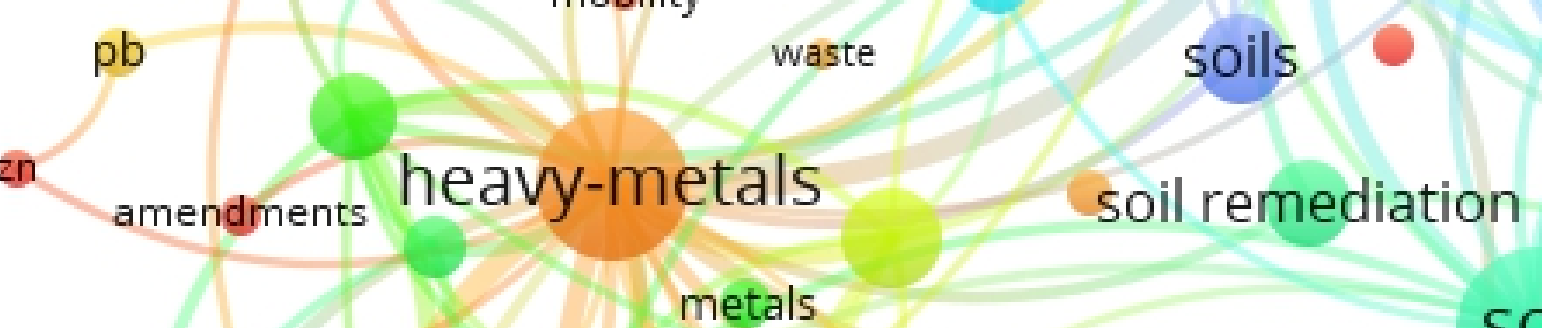

c

metals

sewage-sludge

zinc

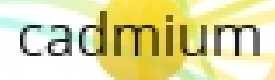

accumulation

plants

phytoremediation

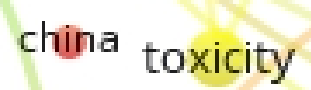

reduction

kinetics

oxidation

\section{porous-media}

groundwater

ic

\& vosviewer

rhizosphere

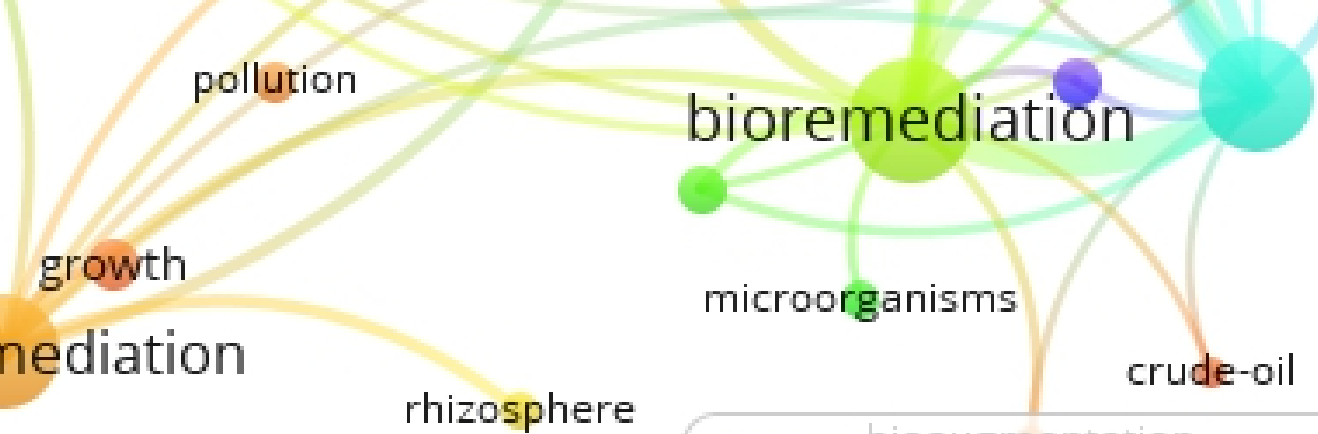

polycycliearomatic-hydrocarbons

water

model

organic-compounds

solubilization

soil

system

surfactants

contaminated soil degradation

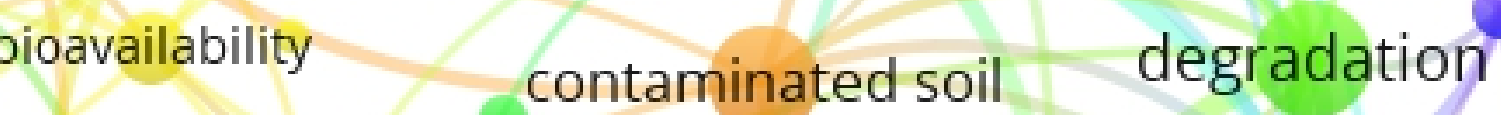

pollution

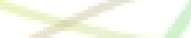

polycycliearomatichydroci

Figure 5 